\title{
What Can We Learn about Smoking from 150 Years of Italian Data?
}

This is the peer reviewed version of the following article:

Original:

Tiezzi, S., Pierani, P., Ciccarelli, C. (2017). What Can We Learn about Smoking from 150 Years of Italian Data?. APPLIED ECONOMIC PERSPECTIVES AND POLICY [10.1093/aepp/ppx047].

Availability:

This version is availablehttp://hdl.handle.net/11365/1013180

since 2018-04-05T18:13:55Z

\section{Published:}

DOI:10.1093/aepp/ppx047

Terms of use:

Open Access

The terms and conditions for the reuse of this version of the manuscript are specified in the publishing policy. Works made available under a Creative Commons license can be used according to the terms and conditions of said license.

For all terms of use and more information see the publisher's website.

(Article begins on next page) 


\title{
Submitted Article
}

\section{What Can We Learn about Smoking from 150 Years of Italian Data?}

\author{
Carlo Ciccarelli, Pierpaolo Pierani, and Silvia Tiezzi*
}

Carlo Ciccarelli is an Assistant Professor in the Department of Economics and Finance, University of Rome Tor Vergata, Italy. Pierpaolo Pierani is an Assistant Professor and Silvia Tiezzi is an Associate Professor, both in the Department of Economics and Statistics, University of Siena, Italy. The authors thank the participants of the XXVIII Annual Conference of the Italian Society for Public Economics, Lecce, September 2016, and participants of the 57th Annual Meeting of the Italian Economic Society (SIE), Milan, October 2016. The authors have benefitted from the feedback provided by seminar participants at the Department of Economic Analysis, University of Valencia (ES). The authors also thank two anonymous reviewers for their useful comments, as well as the Amministrazione autonoma dei monopoli di Stato (Autonomous Administration of State Monopolies, AAMS) and the Ufficio Studi of the Federazione Italiana Tabaccai (Research Office of the Italian Federation of Tobacconists, FIT) for supplying annual data of tobacco consumption for the period 1983-2010. All remaining errors are the responsibility of the authors. ${ }^{*}$ Correspondence to be sent to: silvia.tiezzi@unisi.it.

Submitted 21 October 2016; Editorial Decision 10 September 2017.

\begin{abstract}
This paper estimates dynamic demand models for tobacco consumption in Italy from 1871 to 2010. The empirical analysis is based on an entirely new dataset. Because the tobacco sector was mostly managed by the state, rich and detailed historical documentation is available. Price elasticities are estimated both for aggregate tobacco consumption and its four major components (cigars, cigarettes, cut tobacco, and snuff) for three separate sub-periods: 1871-1913, 1919-1939, and 1946-2010. Elasticities consistently belong to a narrow set. We discuss the public policy implications of a seemingly iso-elastic tobacco demand function.
\end{abstract}

Key words: Long run, tobacco consumption, price and income elasticity of demand.

JEL codes: C22, D12, N43.

This paper offers a detailed quantitative account of secular trends in tobacco consumption in Italy. The case of long-term tobacco consumption represents a fascinating research topic for a number of reasons. First, the sector is very well documented. Since the nineteenth century, the import, production, and sale of tobacco in Italy have often been run by the government under a regime of 
Figure 1 Per-capita consumption of tobacco in the United States, 1880-1995 (pounds)

Source: National Cancer Institute (1998).

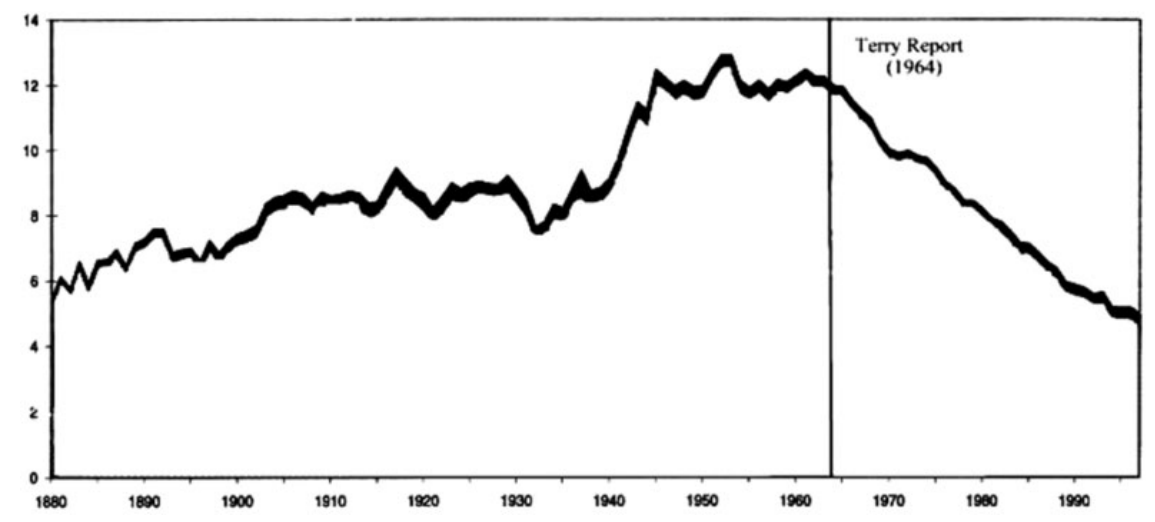

public monopoly, which has led to very accurate official documents and budget reports. ${ }^{1}$ Second, tobacco is typically a normal good and its consumption generates habits. These two characteristics make its taxation particularly appealing for revenue-raising purposes. Third, policy perspectives and individual attitudes towards the consumption of harmful goods have changed dramatically over the last 150 years in most countries. Italy constitutes no exception. Italian policy makers of the nineteenth century were constantly at work to increase per-capita consumption of tobacco, which was a major source of state revenue. $^{2}$ While is it true that pioneering works such as Scalzi (1868) highlighted the negative consequences of tobacco consumption on health, public health concerns were not a social priority of the time, as it also emerges from official documents. ${ }^{3}$ In addition, technical publications of a medical nature were clearly not accessible to the typical illiterate Italian of the time. For both reasons, it seems fair to claim that most consumers were for a long time unaware of the negative effects of tobacco consumption on health.

Today, tobacco is widely recognized as a harmful good. ${ }^{4}$ When did things change? The turning point in the way contemporary societies consider tobacco consumption is conventionally identified with the publication of the first Surgeon General's Report of 1964 (U.S. Department of Health, Education, and Welfare 1964).

The Surgeon General's report stressed, for the first time in an official publication, the existence of a causal relationship between smoking and lung cancer. The report's impact was enormous and its practical effects immediate, as the declining trend in per-capita consumption suggests (figure 1).

\footnotetext{
${ }^{1}$ Madsen (1916) examined the financial and industrial results obtained from the production and sale of tobacco with a special focus on those countries - France, Italy, Austria, Japan, Spain, and Sweden - with a regime of public monopoly.

${ }^{2}$ Public revenues from sales of tobacco accounted for some 10\% of total public revenues (Ciccarelli 2012). In an 1878 report to the Parliament (Atti Parlamentari 1878), the Italian Minister of Finance Agostino Magliani argued that per-capita consumption of manufactured tobacco in Italy (about 0.6 kilograms) was still too low when compared to that of other European countries (about 2.5 in Belgium, 1.5 in Germany, and 0.8 in France).

${ }^{3}$ In a parliamentary address delivered in 1907, Prime Minister Giolitti refused to contemplate banning young people from smoking (as had been done in Japan) on the grounds that it "would have the immediate effect of making them all smoke, just to enjoy breaking the law with little risk of getting caught." Atti Parlamentari (1907).

${ }^{4}$ World Health Organization (2011).
} 
There is general agreement in the medical literature (Warner 2014; Alberg, Shopland and Cummings 2014; Cummings and Proctor 2014) on the fundamental contribution of the 1964 Surgeon General's Report to the decline of the social acceptance of smoking through the advent of legal restrictions on smoking in public spaces, mass media counter-marketing campaigns, and higher taxes on cigarettes. The first cautionary labels had appeared on cigarette packs by 1966. In 1967, anti-smoking advertisements began to air on television. And in 1971, cigarette advertising was banned on television and radio.

The echoes of the report eventually reached Italian policy makers too, and tobacco legislation was updated accordingly. By the end of January 1964, members of the Italian Parliament had asked the government to consider the immediate suspension of any form of advertisement for tobacco "in the light of the recent Terry Report" ${ }^{5}$ Since the mid 1970s, smoking in public places has been banned by law; and fines on the advertising of tobacco products, an illegal activity since the early 1960s, rose considerably after 1983. Tobacco packaging warnings were introduced in $1990 .^{6}$ The most recent legislation (a law passed in 2003, that came into force in 2005) has prohibited smoking in workplaces, bars, and restaurants. Finally, since January 2013, selling tobacco products to individuals under the age of 18 has been declared illegal. $^{7}$

This change of perspective has produced a public policy tradeoff and an economic puzzle. While increasing tobacco consumption is desirable to increase private revenue from sales and public revenue from taxation, decreasing tobacco consumption is desirable for reducing social and external costs from smoking. Whether it is possible to control both tobacco consumption and its negative effects and continue to rely on tobacco taxation as a source of public revenues depends on the relationship between demand and price.

This paper offers the following contributions to the literature on tobacco consumption. First, we build a new dataset covering 150 years. Second, we estimate price and income elasticities, both for aggregate tobacco and its four major components, for three separate sub-periods: 1871-1913, 19191939, and 1946-2010. We find long-run price elasticities of demand to be stable in the range -0.62 to -0.51 over the years 1871 to 2010 . This result is in line with literature referring to more recent decades. Our findings open up the menu of options available to the policy maker facing the problem of tighter budget constraints in times of decreasing tobacco consumption.

\footnotetext{
${ }^{5}$ Chambers of Deputy, Parliamentary Proceedings, Fourth Legislature, Session 30 January 1964, Discussions, 4698-9. Available at: http://www.camera.it/_dati/leg04/lavori/stenografici/sed0090/ sed0090.pdf. It is also interesting to note that the February 1965 issue of "Bollettino di Informazioni", the official magazine of the national association of the managers of tobacco monopoly warehouses, reports that "After the explosion of the Terry report bomb, clearly relating tobacco and cancer", the American government is considering introducing cigarette packet warnings and limitations to advertising to discourage smoking.

${ }^{6}$ The recent legislation on tobacco includes Law no. 584, 11 November 1975 (banning tobacco in public places and transport); Law no. 428, 29 December 1990 (tobacco packaging warnings); Law no. 3, 16 January 2003, the so called "Sirchia law" after the then Minister of Health (banning tobacco in workplaces, bars and restaurants, in force as of 10 January 2005). The annual reports of the Istituto Superiore di Sanità (ISS, Italian National Health Service) provide rich details on the matter. These reports are available at http://www.iss.it/fumo (last accessed, March 2015).

${ }^{7}$ The most recent legislation concerns the e-cigarettes phenomenon. E-cigarettes are essentially a batterypowered cartridge that heats a liquid solution with various flavours (with or without nicotine); these devices are gaining increasing popularity among Italians.
} 
The paper is organized as follows. The next section presents a review of the literature, followed by a section that introduces the 1871-2010 tobacco dataset. In the following section we estimate both the price and income elasticities of demand for aggregate tobacco and its four major components. The next section discusses the public policy implications of the results, and the final section concludes.

\section{Literature Review}

Schoenberg (1933) is credited with providing the first estimate of the demand function for cigarettes. In its early stages, the econometrics of tobacco mainly consisted of estimating static demand equations. Since the end of the 1950s, most studies on cigarette demand have explicitly addressed the addictive nature of smoking; this has led to the introduction of dynamic aspects in the empirical specification. The main consequences of modeling addiction is that the short- and long-run price elasticities of demand can be rather different, because the dependence of current consumption on past consumption implies a lagged demand response to a current price change. In myopic addiction or habit persistence models, for example, current tobacco consumption depends on past consumption, while the impact of current and past choices on future consumption decisions is ignored. Empirical applications of myopic addiction models (Baltagi and Levin 1986, 1992) are mostly based on the works of Houthakker and Taylor (1966) and Pollack (1970); a review is provided by Chaloupka and Warner (2000). Rational addiction models (Becker and Murphy 1988) acknowledge that rational consumers are aware of their addiction and adjust their long-term choices in an optimal way. The crucial implication is that current smoking depends not only on past consumption levels but also on future expected ones, giving rise to long-run elasticities that are usually greater than those estimated from myopic models. Tests of the rational addiction model were initiated by Becker et al. $(1990,1994)$ on aggregate data, and by Chaloupka (1991) on individual data, and have been followed by a sizeable body of empirical literature. $^{8}$ Auld and Grootendorst (2004) showed, though, that aggregate data tend to produce spurious evidence in favor of addiction because they cannot discriminate between addiction and simple correlation in the consumption series. For this reason, addiction models should be estimated on individual data and are therefore not considered in the present study. We instead focus on the information content of aggregate data for an extremely long investigation period.

Turning to studies on tobacco consumption in Italy, the pioneering study with a modern statistical approach is that of Manera (1963), who estimates a static demand model for tobacco with annual time series data covering the period 1900 to 1960. More recent works tend to highlight the addictive nature of tobacco and extend the analysis to a dynamic framework. Tiezzi (2005) estimates a dynamic model of the demand for tobacco using both (pseudo) panel data at the regional level for the years 1972 to 2000, and aggregate time series data at the national level on tobacco expenditure for the years 1960 to 2002. Pierani and Tiezzi (2009) consider the joint consumption of tobacco and alcohol using a set of aggregate annual data covering the

${ }^{8}$ Reviews are provided, among others, by Chaloupka and Warner (2000), Gallet and List (2003), Farrelly, Pechacek, and Chaloupka (2005), and Adda and Cornaglia (2006). 
period 1960 to 2002. Other studies consider the demand for tobacco within a demand system approach that uses weak separability for the grouping of goods (Caiumi 1993; Jones and Giannoni Mazzi 1996; Rizzi 2000; Rizzi and Balli 2002).

A recent strand of literature focuses on the nineteenth century. Ciccarelli (2012) describes the relevant historical sources and provides statistical reconstructions of annual regional tobacco consumption in both physical and monetary terms from 1871 to 1913. Ciccarelli and De Fraja (2014) estimate the demand for tobacco in post-unification Italy using annual data at the provincial level, while Ciccarelli and Elhorst (2017) estimate a spatial dynamic panel data model of early cigarettes diffusion in Italy.

The current literature on tobacco consumption in Italy is thus characterized by very heterogeneous data, ranging from micro to annual aggregate (sales) data and a variety of econometric models. As a consequence, the empirical findings are often difficult to compare. ${ }^{9}$ One contribution of this study is to provide an estimate of the demand for tobacco from a very longrun perspective, using the same estimation approach applied to carefully reconstructed homogeneous time series data.

\section{The Evolution of the Institutional Settings and the New Tobacco Dataset}

Long-run statistical reconstructions of economic indicators are often difficult given the paucity of historical information available. The case of tobacco consumption in Italy constitutes an exception, and is explained by the temporal evolution of the institutional settings behind the tobacco industry, essentially reflecting the rise and decline of state intervention over the last 150 years. $^{10}$

The data used in this work refer to the total annual consumption of tobacco and its major components (snuff, cut tobacco, cigars and cigarettes), in both physical (kilograms) and monetary (Lire/Euro) terms. The time period covered runs from 1871 to 2010. Data from 1871 to 1983 were collected from the annual budget reports of the various institutions (Regía Cointeressata (co-directorship of Tobacco Production) 1869 to 1883, Azienda dei Tabacchi (Tobacco Company) 1884 to 1927, AAMS 1928 to 1983) that were from time to time charged with managing the tobacco business. The annual budget reports share a homogeneous structure and contain sales figures referring to both current and previous years, making it easier to preserve the temporal homogeneity of the time series being reconstructed.

Two points need be clarified. First, the proposed "consumption" data are actually (legal) sales data, referring to ordinary sales of manufactured tobacco for consumption in Italy. These data refer to the cash payments made by authorized dealers (tabaccai) when buying snuff, cut tobacco, cigars, and cigarettes at the monopoly sale warehouses distributed over the Italian territory. The sales considered in our dataset do not include those made at special prices to privileged categories (such as merchant and armed sailors, diplomats, and other minority groups). Furthermore, the sales are those "for

\footnotetext{
${ }^{9}$ The need for a meta-analysis comparing the heterogeneous results of the literature concerning the price elasticity of the demand for tobacco motivated the contribution by Gallet and List (2003).

${ }^{10}$ Vetritto (2005) provides a detailed long-run account of the legal and institutional setting of the tobacco sector in Italy.
} 
domestic consumption", as sales of manufactured tobacco to foreign countries (exports) are excluded.

The last official budget report by the AAMS was published in $1983 .{ }^{11}$ For the period 1984 to 2010, we obtained the data through personal communication with two institutions: the Federazione Italiana Tabaccai, the national association of Italian tobacconists (FIT), and the AAMS. ${ }^{12}$ The FIT dataset includes annual data for 1970 to 2000 on aggregate tobacco consumption in both physical and monetary terms. Aggregate tobacco is also disaggregated into its four major components (snuff, cut tobacco, cigars, and cigarettes). The AAMS dataset includes exactly the same information, but for the years 1994 to 2010 . We were at least able to perform a set of reassuring consistency checks. ${ }^{13}$ The tobacco dataset used in this paper borrows the quantitative information for the years 1983 to 1993 from the FIT dataset, and data for the years 1994 to 2010 from the AAMS dataset.

The full dataset (see the online supplementary appendix) ideally covers the period 1871 to 2010, and includes ten annual time series on tobacco consumption: two series refer to aggregate tobacco (per-capita physical consumption and real price); the remaining series refer to the per-capita consumption and real price of tobacco's four major components. Two additional variables enter the dataset: real income, and real private consumption expenditure. Due to the timing of the two World Wars, three sub-periods were selected for the empirical analysis: 1871 to $1913 ; 1919$ to $1939 ; 1946$ to 2010 .

The real price of tobacco was computed by deflating its nominal price by the ISTAT consumer price index $(1913=1) .{ }^{14}$ The nominal price of tobacco is in fact its unit value, evaluated by dividing the nominal expenditure on tobacco by the corresponding physical consumption. Real income was obtained by deflating Baffigi's GDP series (2011) by the CPI provided by ISTAT (2011). Total current expenditure for private consumption is also taken from Baffigi (2011). All estimations use per-capita variables. Annual 1871 to 2010 population figures refer to individuals aged 15 or over and were obtained by a linear interpolation of census data. ${ }^{15}$

Figure 2 illustrates secular trends of per-capita tobacco consumption $(C)$, of its real price $(P)$, and real income $(Y)$ normalized by their own means. From end to end, per-capita consumption doubled, rising from about one to about two kilograms. But the story is not one of a steady increase. Per-capita consumption declined from 1871 to 1913; it then fluctuated widely around a constant mean in the inter-war period, to rise at an unprecedented pace

\footnotetext{
${ }^{11}$ However, the accompanying text is typically brief and does not allow one to reconstruct temporally homogeneous series of aggregate tobacco consumption and, a fortiori, of their major components. Annual reports of the AAMS for selected years are available at http://www.aams.gov.it/site.php?id=2455.

${ }^{12}$ To get an idea of the wide diffusion over the Italian territory of the FIT network, consider that in the year 2000 there were about 60,000 authorized dealers (tabaccai). Given a national territory (net of forests) of around 233,000 square kilometers, the territorial density of tobacco shops (tabaccai) is quite high (60/233).

${ }^{13}$ First, we compared the 1970 to 1983 FIT data against those reported in the official standard annual budgets of the AAMS. The comparison was made separately for each component of total tobacco sales (snuff, cut tobacco, cigars, and cigarettes), in both physical and monetary terms, separately by years. Second, we compared the AAMS data against the FIT data on total sales of tobacco for the years 1980 to 1994. Finally, we compared the 1984 to 2010 data against the figures published annually by ISTAT (Italian National Institute of Statistics).

${ }^{14}$ The consumer price index $(1913=1)$ is reported in Istat $(2011)$.

${ }^{15}$ Data and intermediate estimation results are available from the authors upon request.
} 
Figure 2 Secular trends in $C, P$, and $Y$

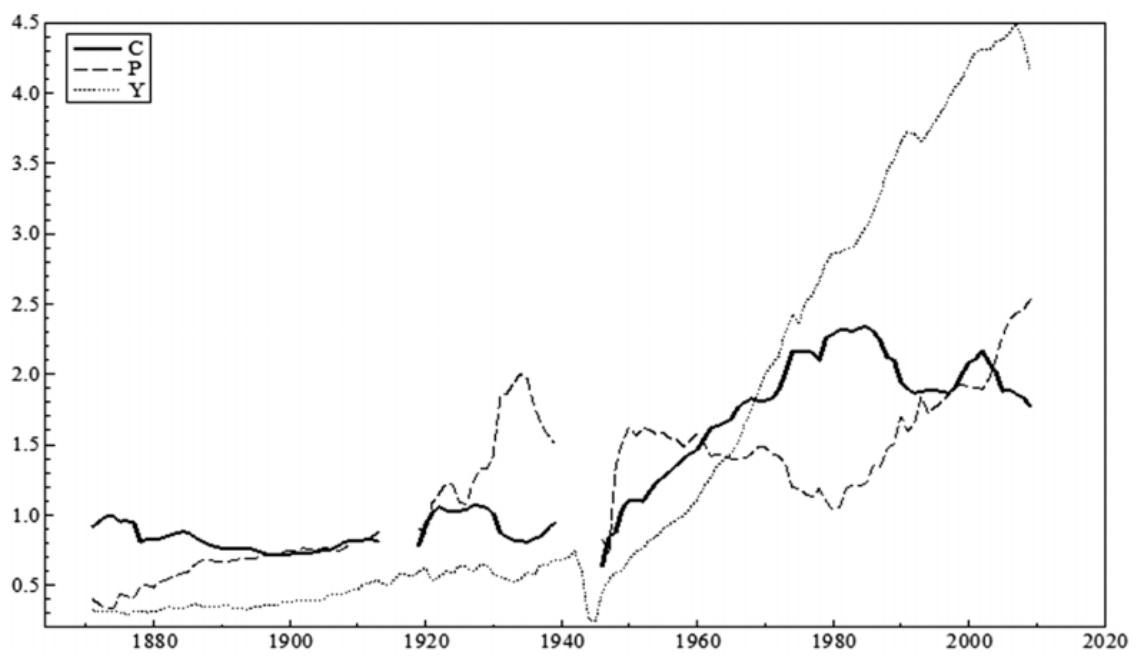

from 1945 to 1985, when it reached its highest level ever. ${ }^{16}$ The positive trend was reversed in the early 1980s, and from 1985 onwards per-capita consumption declined to the level of the 1970s. ${ }^{17}$ Moreover, there is a general negative relationship between tobacco prices and consumption levels. This regularity is not obvious when dealing with goods like tobacco, triggering habits or addictions, and it corroborates our choice to specify demand functions that do not explicitly account for addiction. ${ }^{18}$ Comparing Figures 1 and 2, two points emerge. First, a long-term decline in per-capita tobacco consumption occurred both in the United States and in Italy after almost one century of consumption growth. Second, the turning-point in the trend occurs in the mid-1960s for the United States and the mid-1980s for Italy, a delay of about two decades.

\section{Empirical Results}

The aim of this section is to estimate short- and long-run price and income elasticities of tobacco demand in Italy from the post-unification years until

\footnotetext{
${ }^{16}$ The inter-war years registered a general reduction in international trade. For Italy, autarchy represented the new faith. Historical sources clearly show that the Italian imports of tobacco (both the leaves and the manufactured products) fell considerably during the inter-war period.

${ }^{17}$ The rapid upturn occurring after the turn of the century admittedly appears odd. An explanation can be found in Joossens and Raw (2008). These authors provide estimates of the amount of seized tobacco (in tons) in Italy around the turn of the century, and find that from 1998 to 2002, legal cigarette sales increased by 19\% in Italy as a whole, by $121 \%$ in Campania, and by 55\% in Apulia. The authors conclude that illicit cigarette sales became largely unavailable during this period, forcing smokers to buy cigarettes in legal markets. For more about estimating price elasticities when smuggling is present, see Gruber, Sen, and Stabile(2003).

${ }^{18}$ Our data do not detect smuggling. Publicly available data on smuggling are scarce (Gilmore et al. 2014) and, in the Italian case, they refer only to the most recent years (Gallus et al. 2003). The available information suggests that smuggling in Italy increased in the late 1980s, and accounted for 10\% to 30\% of cigarette sales in the early 1990s (Gallus et al. 2003 and 2009). Smuggling then declined one decade later due to increased control of the supply chain of cigarettes and to new decrees on smuggling enforced in the early 2000s, but also due to the NATO intervention in Kosovo in 1999, which led to stricter control of the Italian coasts. From 2000 onwards, interest in reliable smuggling data grew rapidly in Europe (Joossens et al. 2014), leading to useful data collection. However, the time span of these data is too recent to apply to the present study.
} 
Table 1 Descriptive Statistics

\begin{tabular}{|c|c|c|c|c|c|c|}
\hline \multirow[b]{2}{*}{ Variable } & \multicolumn{2}{|c|}{ 1871-1913 } & \multicolumn{2}{|c|}{ 1919-1939 } & \multicolumn{2}{|c|}{ 1946-2010 } \\
\hline & Mean & Std. dev. & Mean & Std. dev. & Mean & Std. dev. \\
\hline$C_{t}$ & 1.621 & 0.117 & 1.673 & 0.184 & 2.430 & 0.491 \\
\hline$P_{t}$ & 0.006 & 0.001 & 0.014 & 0.004 & 0.016 & 0.004 \\
\hline$Y_{t}$ & 0.741 & 0.138 & 1.060 & 0.077 & 3.310 & 1.486 \\
\hline
\end{tabular}

Note: For a detailed description of the variables, see the previous section.

2010. The following subsection deals with the empirical analysis of aggregate tobacco demand, based on cointegration tests and an error-correction mechanism (Engle and Granger 1987; Johansen 1988; Doornik 1998). Following that, we further explore the pattern of consumption of the four major tobacco components (snuff, cut tobacco, cigarettes and cigars) by estimating a complete demand system. The purpose is to provide additional insights for the seemingly iso-elastic demand function we observe over one and half centuries.

\section{Aggregated Analysis}

We proceed in two steps. First, the time series properties of the variables are examined to determine their order of integration. A long-run relationship of tobacco demand is then estimated via OLS: ${ }^{19}$

$$
C_{t}=a_{0}+a_{1} Y_{t}+a_{2} P_{t}+u_{t}
$$

where $C_{t}$ and $P_{t}$ represent per-capita consumption and the real price of tobacco, respectively, and $Y_{t}$ denotes real per-capita income (see figure 2 ). The stationarity of the OLS residuals - verified with unit roots tests - is considered evidence of an equilibrium relationship between $C, Y$, and $P$ that are said to be "cointegrated". In the second step, the residuals of the cointegrating regression are used as an explanatory variable in an error correction model (ECM):

$$
\Delta C_{t}=b_{0}+b_{1} \Delta Y_{t}+b_{2} \Delta P_{t}+b_{3} \hat{u}_{t-1}+\varepsilon_{t}
$$

where the parameter $b_{3}$ of the error term $\hat{u}_{t-1}$ measures the extent to which consumption tends to revert to long-run equilibrium. Table 1 complements figure 2 and provides descriptive statistics for the physical consumption of tobacco $(C)$ in kilograms, real per-capita income $(Y)$ in Euros, and real price of tobacco $(P)$ in Euro $/ \mathrm{kg}$.

\section{Stationarity Tests and Cointegration Analysis}

To determine whether the model variables are stationary (as well as their order of integration) two alternative tests are used: ADF (Dickey and Fuller

\footnotetext{
${ }^{19}$ The empirical literature provides different specifications of the demand functions (Cameron 1998; Gallet and List 2003). The linear form is here preferred to the more popular double-log specification because it is not bound to having constant elasticities. This hardly seems a tenable assumption when using very long time-series data, and factors that influence tobacco demand responsiveness have possibly changed, even considerably.
} 
1979) and KPSS (Kwiatkowski et al. 1992) unit root tests. The ADF test consists of running the following regression:

$$
\Delta y_{t}=\mu+\lambda t+\alpha y_{t-1}+\sum_{i=1}^{p} \gamma_{i} \Delta y_{t-i}+\varepsilon_{t}
$$

and testing whether the coefficient of $y_{t-1}$ is zero, that is, $H_{0}: \alpha=0$ versus $H_{1}: \alpha<0$. The number of augmenting lags $p$ is chosen so as to ensure white noise disturbances. The optimal lag length is selected according to modified Akaike (AIC) and Schwartz (SC) information criteria (Ng and Perron 2001). ${ }^{20}$

If the null of a unit root cannot be rejected, the test is repeated on the differenced series to check whether one can reject a higher order of integration in favor of I(1). The KPSS unit root test differs from the ADF test in that the series $y_{t}$ is assumed to be stationary under the null hypothesis. ${ }^{21}$

The two test statistics indicate that the levels of the three series are nonstationary. In contrast, when the first difference of the variables is examined, the null hypothesis of a unit root process can be strongly rejected (see table B.1 in the online supplementary appendix for details). ${ }^{22}$ Therefore, both tests indicate consistently that the variables $C_{t}, P_{t}$, and $Y_{t}$ are best described as nonstationary $\mathrm{I}(1)$ series. $^{23}$

Given that $C_{t}, P_{t}$, and $Y_{t}$ are nonstationary I(1) series, we initially estimate equation (1) via OLS. Cointegration is supported if the null of a unit root is rejected for the OLS residuals. The estimated long-run relationship is shown in table 2. Both real price and income variables confirm sign expectations and significantly determine tobacco consumption in Italy in each subperiod. Previous econometric studies (Chaloupka and Warner 2000; Saffer and Chaloupka 1999) find negative and significant effects of qualitative and control policy variables (e.g., smoking restrictions, a ban on smoking for minors, health information, warning labels on packaging, and demographic factors) on tobacco consumption. Accordingly, we have modelled such a potential impact adding ad hoc dummies and a time trend in the long-run regression. These proxies, however, were not statistically significant, and eventually they were dropped to save degrees of freedom. ${ }^{24}$

\footnotetext{
${ }^{20}$ The critical values of the $\mathrm{t}$-statistics, as well as the relevant $\mathrm{p}$-values are based on MacKinnon (1996).

${ }^{21}$ The critical values of this test are based on Sephton (1995).

${ }^{22}$ The results for the second period (1919 to 1939) are reported for the sake of completeness. These results are based only on 21 observations, which makes any conclusion in principle weak. Nonetheless, with the caution of the case, the results of both type of tests show that the three series are nonstationary in the intermediate sub-period too.

${ }^{23}$ In the presence of structural change, though, the ADF-type tests cannot be considered conclusive in that they are known to be biased towards the non-rejection of the null. Hence, we have formally tested for unit roots in the presence of structural instability (Perron 1989). The results (available upon request) reveal that the unit root hypothesis receives support (at the 5\% significance level) after considering a structural change effective at 1980. The break date coincides with a rapid increase in the real price of tobacco (see figure 2). Plausibly, it also reflects the (much delayed) impact of international tobacco legislation and smoking restrictions of the early 1960s on Italian consumers.

${ }^{24}$ The role of smuggling is also of concern. In the absence of available data, one way to control for smuggling when using a time series of aggregate data is to add the price of tobacco products in neighbouring states among the explanatory variables of the demand equation, as in Baltagi and Levin (1986). Other studies have made use of smuggling indices (Becker, Grossman and Murphy 1994) or proxies (Tiezzi 2005). In an attempt to control for smuggling, we added among the explanatory variables the quantity of foreign tobacco consumed in Italy, in inverse ratio, used as a proxy of smuggling. We did not get significant results. In addition, such a proxy was available only for the years 1972-2000.
} 
Table 2 Estimated Cointegration Relationships

\begin{tabular}{lccc}
\hline Variable & $\mathbf{1 8 7 1 - 1 9 1 3}$ & $\mathbf{1 9 1 9 - 1 9 3 9}$ & $\mathbf{1 9 4 6 - 2 0 1 0}$ \\
\hline Constant & $-1.823^{* * *}$ & $1.106^{* * *}$ & $2.786^{* * *}$ \\
$P_{t}$ & $-155.451^{* * *}$ & $-27.778^{* * *}$ & $-78.935^{* * *}$ \\
$Y_{t}$ & $1.080^{* * *}$ & $0.417^{* *}$ & $0,338^{* * *}$ \\
$\bar{R}^{2}$ & 0.842 & 0.928 & 0.866 \\
$F$-statistic & $90.381^{* * *}$ & $93.519^{* * *}$ & $86.430^{* * *}$ \\
Diagnostic Tests & Value & Value & Value \\
\hline Serial correlation & $6.361^{* * *}$ & 0.975 & $46.495^{* * *}$ \\
Normality & 0.496 & 1.428 & 1.184 \\
Misspecification & 0.567 & 0.441 & 0.698 \\
Stability & 0.511 & -1.446 & -1.330 \\
\hline
\end{tabular}

Note: Asterisks ***,**, and * denote significance at the 1\%,5\%, and $10 \%$ levels, respectively. Serial correlation: Breusch-Godfrey test; Normality: Doornik-Hansen test; Misspecification: Ramsey RESET test; Stability: Harvey-Collier t-statistic.

The residual-based ADF and KPSS test statistics (see table B.2 in the online supplementary appendix for details) consistently indicate that the null of nonstationarity of the residuals from the long-run relationship can be rejected at the $5 \%$ level in both the first and second periods and at the $10 \%$ level in the more recent period (1946 to 2010). Hence, based on the stationarity of the OLS residuals it can be concluded that $C_{t}, P_{t}$, and $Y_{t}$ are cointegrated.

In principle, there could be multiple linear combinations of these variables which are $\mathrm{I}(0)$. In order to determine the number of cointegrating vectors, we have used the Johansen approach. In both the first and the last subperiods, the two statistics indicate that we can reject the null of no cointegrating relationships at the $1 \%$ significance level, and suggest that there exists only one stationary relationship between the nonstationary variables included in the model (the results of the trace test and the maximal eigenvalue test are summarized in table B.3 in the online supplementary appendix). This finding supports the single-equation Engle-Granger approach.

\section{Error Correction Model}

We next turn to the estimation of the error correction model (Engle and Granger 1987). Table 3 reports the OLS estimates. Given that all variables are stationary, the standard test statistics do have the conventional limit distributions. All relevant coefficients have the expected sign and are statistically significant, with the exception of $\Delta Y_{t}$, which, in the first period (1871 to 1913), does not significantly affect the changes in tobacco consumption. Changes in lagged consumption $\Delta C_{t-1}$, price $\Delta P_{t}$, and income $\Delta Y_{t}$ (in the recent sub-period) are all statistically significant at the $1 \%$ and $10 \%$ levels, respectively. The estimated ECM coefficients are negative and significant in all periods, indicating that the null of the cointegrating hypothesis is not rejected at the $5 \%$ level, and that the demand for tobacco partially reverts to long-run equilibrium after any short-run imbalance. The speed of adjustment, though, differs strongly between periods.

The ECM model appears to be well-specified since it passes a list of standard diagnostic tests. The only discordant finding is the Ramsey's RESET 
Table 3 Estimated ECM Relationship

\begin{tabular}{lccc}
\hline Variable & $\mathbf{1 8 7 1 - 1 9 1 3}$ & $\mathbf{1 9 1 9 - 1 9 3 9}$ & $\mathbf{1 9 4 6 - 2 0 1 0}$ \\
\hline Constant & 0.004 & 0.002 & 0.013 \\
$\Delta C_{t-1}$ & $0.467^{* * *}$ & $0.420^{* * *}$ & $0.349^{* * *}$ \\
$\Delta P_{t}$ & $-120.486^{* * *}$ & $-17.274^{* * *}$ & $-54.590^{* * *}$ \\
$\Delta P_{t-1}$ & $64.225^{* *}$ & & 2.134 \\
$\Delta P_{t-2}$ & $-62.798^{* *}$ & & -5.620 \\
$\Delta Y_{t}$ & 0.274 & -0.110 & $0.158^{*}$ \\
$\Delta Y_{t-1}$ & $-0.395^{* *}$ & & -0.066 \\
$\Delta Y_{t-2}$ & $0.810^{* *}$ & & -0.075 \\
$\hat{u}_{t-1}$ & $-0.432^{* *}$ & $-0.582^{* * *}$ & $-0.120^{* * *}$ \\
$\bar{R}^{2}$ & 0.521 & 0.753 & 0.470 \\
F-statistic & $4.733^{* * *}$ & $38.051^{* * *}$ & $7.655^{* * *}$ \\
Diagnostic Tests & Value & Value & Value \\
\hline Serial correlation & 2.194 & 0.088 & 0.352 \\
Normality & 4.019 & 1.957 & 0.560 \\
Misspecification & $13.326^{* * *}$ & 2.661 & 0.039 \\
Stability & -1.553 & -0.602 & -0.521 \\
\hline
\end{tabular}

Note: Asterisks ***, **, and * denote significance at the 1\%,5\%, and $10 \%$ levels, respectively. Serial correlation: Breusch-Godfrey test; Normality: Doornik-Hansen test; Misspecification: Ramsey RESET test; Stability: Harvey-Collier t-statistic.

Table 4 Estimated Demand Elasticities

\begin{tabular}{llrrr}
\hline Elasticity & & \multicolumn{1}{c}{$\mathbf{1 8 7 1 - 1 9 1 3}$} & \multicolumn{1}{l}{$\mathbf{1 9 1 9 - 1 9 3 9}$} & \multicolumn{1}{c}{$\mathbf{1 9 4 6 - 2 0 1 0}$} \\
\hline Price & Short-run & $-0.477(0.118)$ & $-0.248(0,081)$ & $-0.349(0.101)$ \\
& Long-run & $-0.615(0.033)$ & $-0.422(0.026)$ & $-0.505(0.118)$ \\
Income & Short-run & $0.125(0.101)$ & $-0.047(0.061)$ & $0.216(0.121)$ \\
& Long-run & $0.494(0.044)$ & $0.264(0.104)$ & $0.461(0.062)$ \\
\hline
\end{tabular}

Note: Values are at the sample mean. Approximate asymptotic standard errors appear in parentheses.

test in the first period, which shows that there is some departure from the null of the maintained model.

\section{Price and Income Elasticities}

Table 4 reports elasticity estimates at the sample mean of the relevant period. The estimated elasticities have the expected signs, that is, the demand for tobacco is negatively (positively) related to price (income) both in the short and in the long run. Second, the short-run elasticities are always smaller (in absolute terms) than the response in the long-run, as expected when dealing with the consumption of addictive goods. Third, changes in income tend to affect tobacco consumption only in the long-run (all shortrun income elasticities are numerically negligible and not significant). Indeed, in the long run tobacco is a normal good and its responsiveness to income is more or less constant over time (from 0.49 to 0.46 ). Fourth, estimates of both short- and long-run elasticities confirm that tobacco demand is inelastic to its own price, and increasingly so over time $(-0.48$ and -0.62 , 
Figure 3 Time path of long-run elasticities

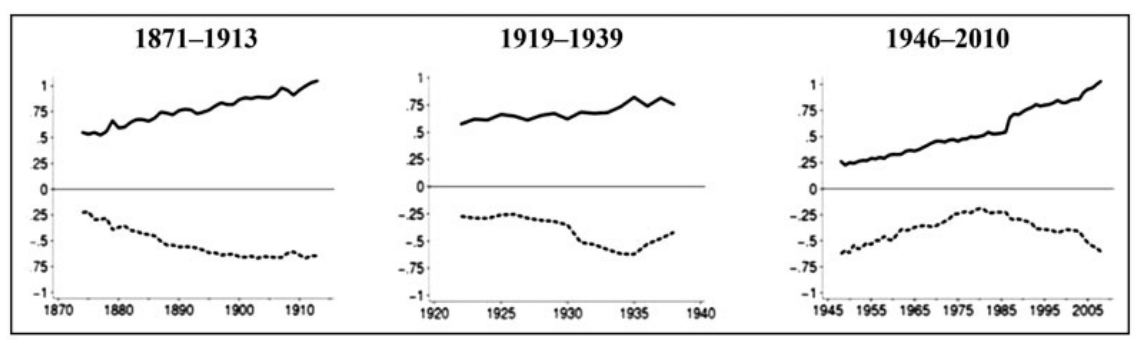

respectively, in the first period, and -0.35 and -0.51 , respectively, in the last period).

For the recent period (1946 to 2010), our estimates appear in line with those reported in the international literature, with the prevailing values of price elasticities ranging between -0.3 and -0.5 (Cameron 1998; Chaloupka and Warner 2000; Gallet and List 2003). Turning to the Italian case, previous studies find price elasticities with a median value of -0.41 and -0.75 for the short- and long-run cases, respectively (Jones and Giannoni-Mazzi 1996; Rizzi 2000; Escario and Molina 2001; Gallus et al. 2003; Tiezzi 2005; Pierani and Tiezzi 2009). Finally, the work by Nguyen, Rosenqvist, and Pekurinen (2012), which is close in spirit to our approach, presents estimates of the short-run price and income elasticities of cigarette demand of -0.373 and 0.098 , respectively (although the latter is not statistically significant).

Figure 3 accounts for the temporal profile of price and income elasticities. The bold lines, always above zero, represent long-run income elasticities, while the dotted lines, always below zero, refer to long-run price elasticities. ${ }^{25}$ Income elasticities are always within the interval $[0.25,1]$, making tobacco a normal good. This result should be taken with a grain of salt. Aggregate time series may not be the appropriate data to identify the true income elasticity for tobacco products, and the positive income elasticities found in this study may possibly be caused by other unobservables. For example, one would expect that the spread of information about the health consequences of smoking, antismoking activities and admonitions on packaging in the second half of the more recent period should have reduced the income elasticity of tobacco products. ${ }^{26}$

Turning to price elasticities, even from a secular perspective, the long-run price elasticity of tobacco has remained in the range of -0.62 to -0.51 . This finding seems peculiar when one considers how radically the perspective of both Italian policy makers and consumers regarding tobacco has changed over time. Such a twist is well-represented by the inverted U-shape of the price elasticity of demand in the third sub-period starting at -0.62 in 1948, reaching a threshold value of -0.19 in 1980 , and going back to -0.61 by

\footnotetext{
${ }^{25}$ Estimated elasticities are always significant because confidence intervals (not shown here) never include zero. The time series of long-run elasticities, shown in figure 3, were obtained by extrapolating, separately for each sub-period, the estimated coefficients $a_{1}$ and $a_{2}$ of equation (1).

${ }^{26}$ Respondent-level cross-sectional data may be better suited for this task. For example, in a very interesting study, Binkley (2010) investigates the relationship between income and smoking, developing a model in which income serves both as budget constraint and as a source of future utility. This author's results suggest that poor health behaviour by low-income consumers may be economically rational. Moreover, given that the great reduction of the smoking population that has occurred over the last decades has been smaller for those with less income, cigarettes have switched from being a normal to being an inferior good.
} 
Figure 4 Per-capita consumption of tobacco in Italy: major components, 1871-2010 (kg)

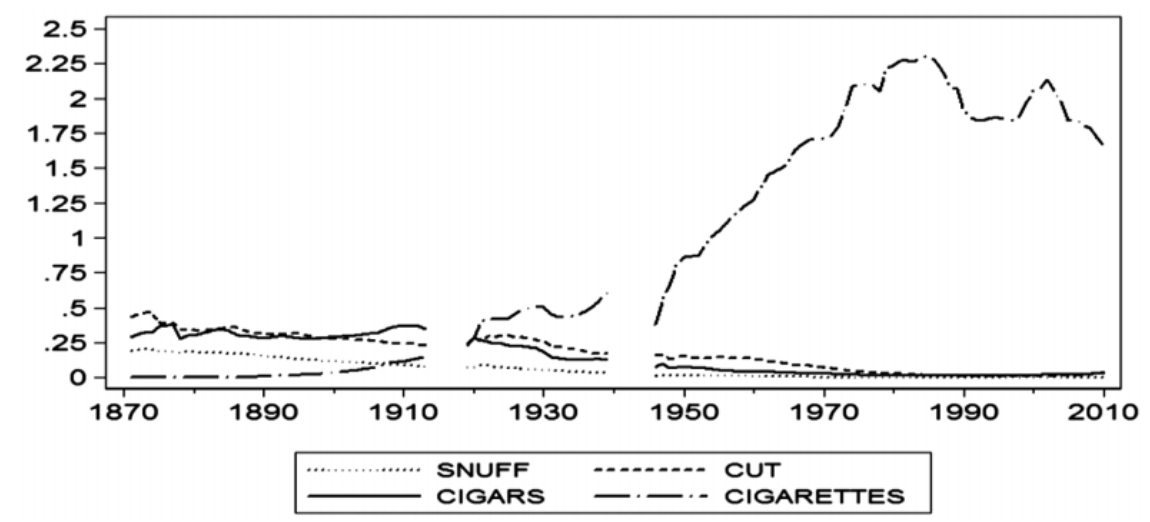

2008. Between 1946 and 1980, smoking behavior in Italy was still a status symbol associated with female emancipation, subliminal movie messages and cultural transformation, but not yet associated with health problems. From 1980 onwards, though, the growing concerns about the negative health consequences as well as the coming into effect of the anti-smoking laws might have caused the elasticity to increase again. ${ }^{27}$ Thus, the inverted U-shaped price elasticity of demand may well reflect the shift of tobacco from a sort of conspicuous habit to a social stigma.

\section{Disaggregated Analysis}

In this section we investigate patterns of per-capita expenditure on the four tobacco products. The evolution of per-capita consumption on the four tobacco products is shown in figure 4 . In the late nineteenth century and early twentieth century, the largest expenditure share was on cigars, followed by cut tobacco, but their consumption gradually declined over time to around zero. Expenditure on cigarettes was low in the late nineteenth century, but increased to $2.5 \%$ of total outlay (amounting to over $96 \%$ of the expenditure on tobacco products) in the most recent years.

In fact, as shown by figure 5, over time there has been an almost total replacement of the other tobacco products by cigarettes. Indeed, in 1871 snuff, cut tobacco, and cigars covered 99\% of tobacco expenditure, but in 2010 cigarettes represented $97 \%$ of such expenditure. The historical shift in individual preferences and habits with regard to tobacco products explains these trends. For example, the use of chewing tobacco and snuff was reduced by anti-spitting laws enacted in the late 1800s and early 1900s, which were intended to minimize the spread of tuberculosis and other infectious diseases (O'Connor 2011).

In recent decades, the health hazards of active and passive smoking have been definitively recognized, and smoking behavior has increasingly become stigmatized. Smokeless tobacco (e.g., snuff) does not imply passive smoking, and therefore it may carry less social stigma than smoking. It is thus of particular interest to explore the substitution relationships between smoking (cigarettes, cigars, and cut tobacco) and smokeless (snuff) types of tobacco.

\footnotetext{
${ }^{27}$ The first anti-smoking law in Italy was Law n. 584/1975, enacted on November 11, 1975, which prohibited smoking on public means of transportation, in hospitals, theatres, museums, universities, and public libraries.
} 
Figure 5 Tobacco expenditure: budget shares, 1871-2010

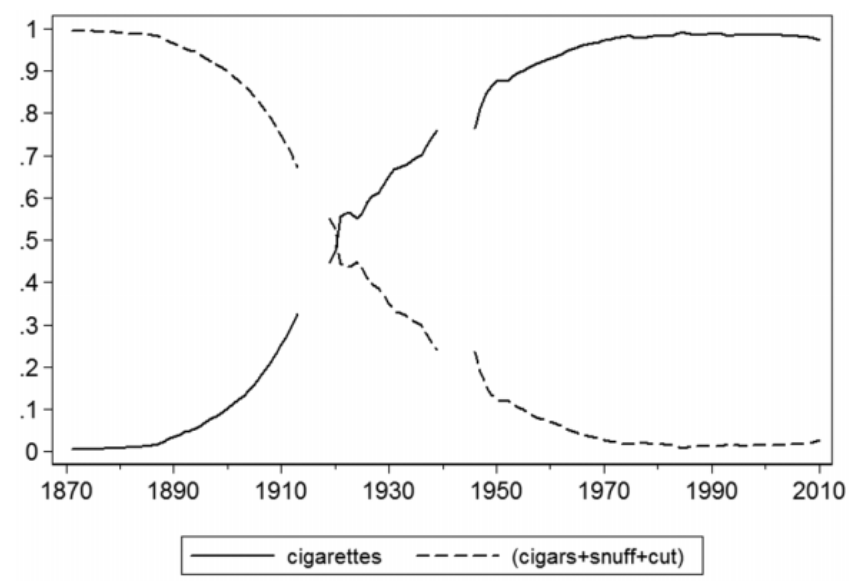

To provide information on substitution/complementarity relationships, we compute own and cross-price elasticities for the four tobacco products from the parameters of a complete demand system, which includes a composite commodity for the remaining nondurables. The demand system was estimated separately for the three periods 1871-1913, 1919-1939 and 19462010. The functional form chosen is the well-known Almost Ideal Demand System (AIDS; Deaton and Muellbauer 1980). The estimated demand functions are the following budget shares:

$$
w_{i t}=\alpha_{i}+\sum_{j} c_{i j} \ln p_{j t}+b_{i} \ln \left(\frac{Y_{t}}{P_{t}}\right)+u_{i t}
$$

where $Y_{t}$ is total expenditure in year $t, p_{j t}$ is the price of the $j$ th tobacco product, $P_{t}$ is approximated by the Stone linear price index, defined as $\ln P_{t}=\sum_{i} w_{i} \ln p_{i t}$, the parameters $c_{i j}$ are defined as $c_{i j}=1 / 2\left(c_{i j}^{*}+c_{j i}^{*}\right)=c_{j i}$, and $u_{i t}$ is the stochastic error term. A linear time trend is also included. From the demand system (4), the matrix of uncompensated price and income elasticities can be calculated, as in Green and Alston (1990). Along the lines of our previous aggregate analysis, we investigate here the time series properties of variables used in equation (4), that is, budget shares in levels, prices in logarithms, and a measure of per-capita income deflated by the Stone price index in order to specify the correct dynamic specification (Attfield 1997). Both the ADF and Phillips-Perron test statistics suggest that the unit root hypothesis cannot be rejected at the $5 \%$ level of significance for each variable included in equation (4). The next step is to test the hypothesis of cointegration using the Engle and Granger (1987) methodology. We find evidence of stationary OLS residuals and conclude that all the variables in equations (4) are I(1) and cointegrated. The estimated ECM is:

$$
\Delta w_{i t}=\xi_{i} \Delta w_{i t-1}+\sum_{j} c_{i j} \Delta \ln p_{j t}+b_{i} \Delta \ln \left(\frac{Y_{t}}{P_{t}}\right)-\lambda_{i} \mu_{i t-1}+\varepsilon_{i t}
$$

where $\mu_{i t-1}$ are the estimated residuals from cointegrating equations (4). The estimate of the error correction terms $\lambda_{i}$ are all statistically significant and 
have the correct signs, indicating that deviations from long-run equilibrium are corrected within the time period. ${ }^{28}$ Table 5 shows long-run and shortrun uncompensated (Marshallian) price and income elasticities, along with their standard errors derived from the estimated parameters of equations (4) and (5), respectively, (using the fitted budget shares calculated at the sample mean of the investigation periods, i.e., 1871-1913, 1919-1939, and 19462009). ${ }^{29,30}$ Here, we focus on the most interesting equilibrium, that is, own and cross-price elasticities and their pattern over time (table 5). The last column displays each commodity's income elasticity of demand. All own-price elasticities in the long run are significant, with the correct sign, and satisfy the theoretical properties. The long-run price elasticity of cigarettes goes from -0.811 in the pre-war period to -0.253 in the latest period, indicating that cigarettes are an increasingly price-inelastic good. This pattern is consistent both with the literature (Gallet and List 2003) and with our findings. The long-run price elasticity of cigars seems rather stable over time, going from -0.660 in the first time period to -0.676 in the most recent period. Own price elasticities for snuff and cut tobacco are not relevant in the third period because the budget shares for these products amount to almost zero. Overall, these patterns are consistent with a story of gradual substitution for other tobacco products by cigarettes, driven by the secular changes in preferences described above.

Substitution relationships are particularly interesting for both their public finance and public health implications. When faced with price differentials, consumers may substitute a related product for the desired one, for example, cut tobacco used for roll-your-own (RYO) cigarettes replacing packed cigarettes. In principle, public policy could manipulate such substitution behavior by setting the tax structure so as to meet policy goals, such as incentivizing smokers to adopt less hazardous forms of tobacco. Smoked tobacco other than cigarettes, such as cigars and cut tobacco used for RYO, have now been shown to pose similar health burdens (O'Connor 2011). However, smokeless tobacco products such as snuff or chewing tobacco do not involve passive smoking and may therefore be preferable for public health purposes.

Focusing on long-run cross-price elasticities, table 5 shows that cigars become an increasingly strong substitute for cut tobacco over time $(0.148$ in the first sub-period; 0.510 in the third sub-period) and a strong complement of cigarettes in the third sub-period $(-1.078)$. On the other hand, cigarettes are a weaker complement of cigars $(-0.009$ in the first sub-period and -0.024 in the third sub-period), meaning that the demand for cigarettes declines much less following an increase in the price of cigars than the decline in the demand for cigars following an increase in the price of cigarettes. As expected, smokeless tobacco (snuff) in the first investigation period is a substitute for smoked tobacco (cigarettes and cut). In the last investigation period we instead find a strong complementarity between snuff and cigarettes $(-1.772)$. These last results have to be considered with caution given the negligible budget share of snuff tobacco. At the same time, cigarette

\footnotetext{
${ }^{28}$ Results of unit root tests and ECM estimation are available from the authors upon request.

${ }^{29}$ Estimates of short-run elasticities are obtained using the same formulas as described in Green and Alston (1990) and the estimated parameters of equation (5), while their long-run counterparts use the estimated parameters of the cointegration equations (4).

${ }^{30}$ As stressed previously, the results for the second period (1919-1939) are reported for the sake of completeness. Given the low number of observations (21) any conclusion is in principle weak.
} 


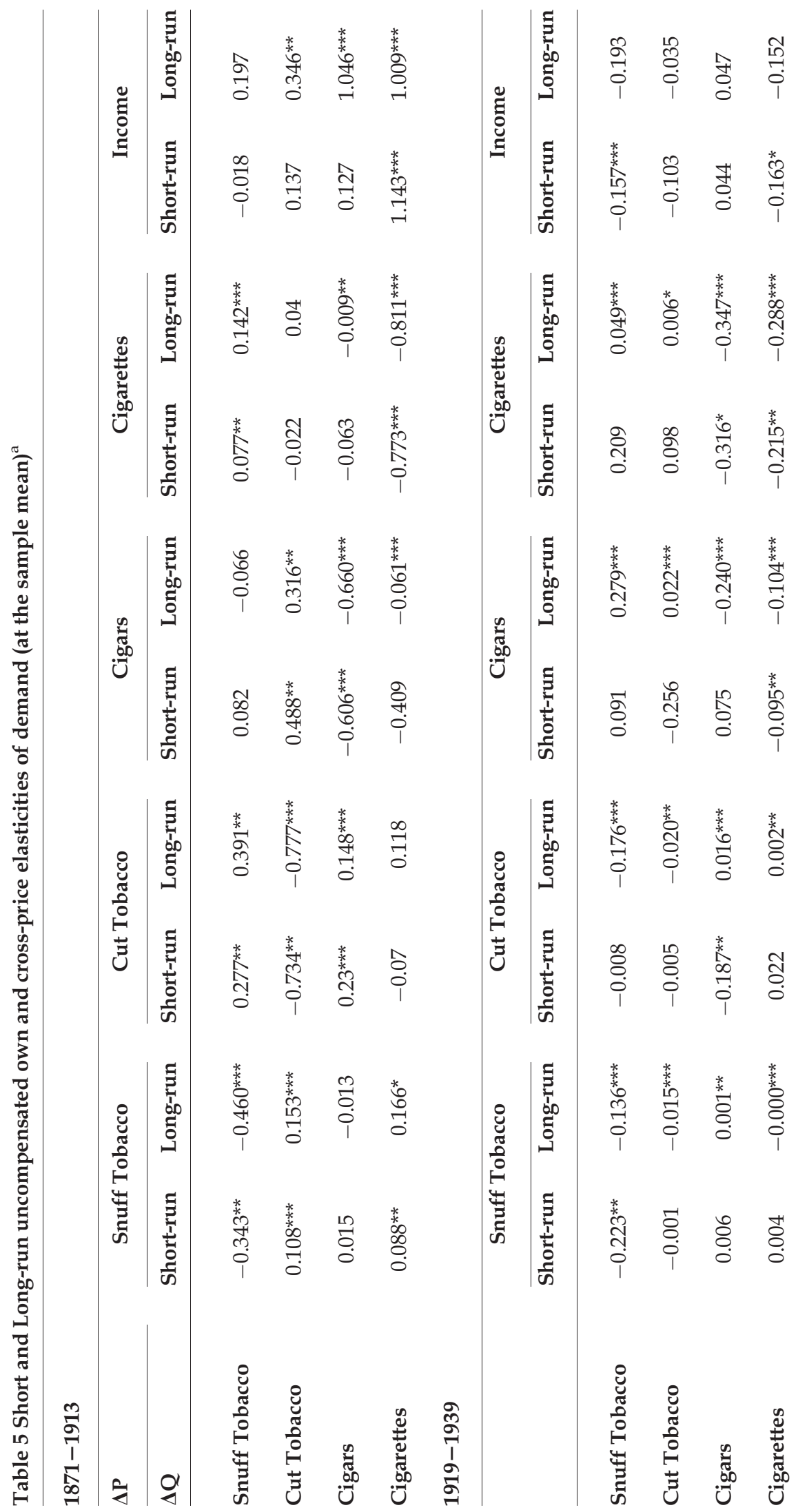




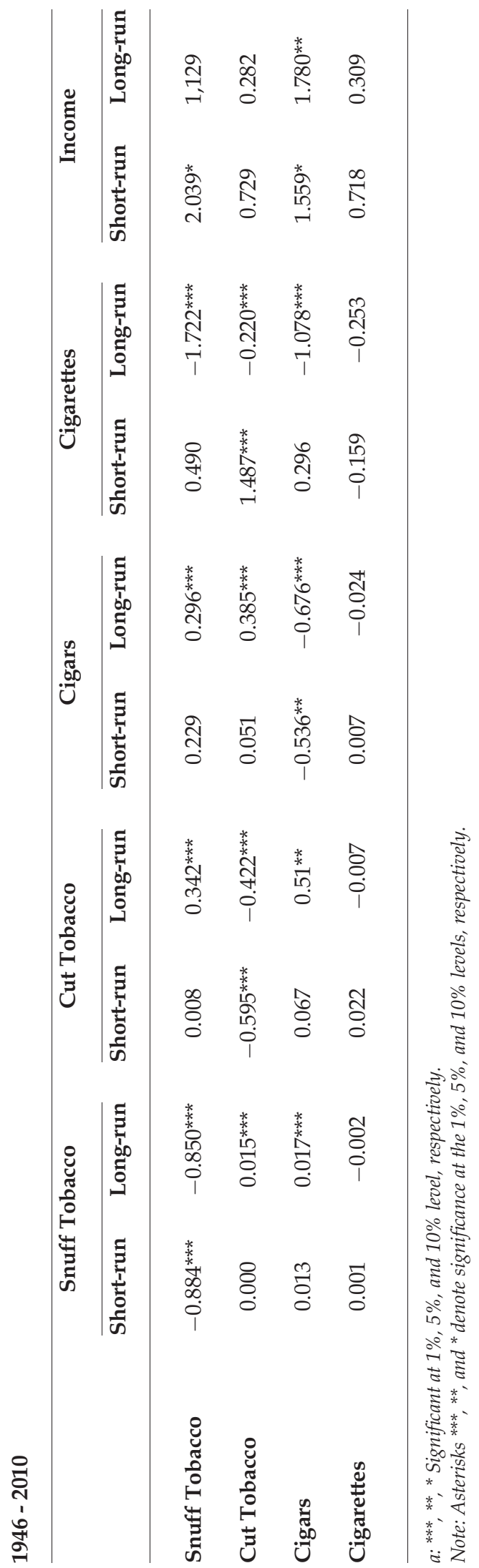


consumption is insensitive to variations in the price of other products. ${ }^{31}$ The disaggregated analysis thus highlights a clear replacement of both smokeless and smoked tobacco by cigarettes over time. We also used the Slutzky equation to decompose the cross-price elasticities for the period 1946-2010 into the Hicksian price effect and the income effect. ${ }^{32}$ We find substitution among the four tobacco products in the short run and complementarity in the long run. One interpretation of this finding is that smokers start as single-product consumers and turn to other tobacco products in the short run after a price increase in their preferred tobacco product. However, each tobacco product may serve as a gateway to nicotine addiction such that multiple tobacco product use becomes more prevalent in the long run.

\section{Implications}

An almost stable price elasticity of demand for tobacco over one-and-a-half centuries is a novelty considering that prices and quantity consumed have changed dramatically over the last 150 years. This finding mimics an isoelastic demand curve for which the price elasticity of demand does not vary with price and quantity. As long as the constant price elasticity of demand $\eta$ is less than one, a price increase will always increase total expenditures. ${ }^{33}$ An increasing expenditure level over time, coupled with a structure of tobacco taxation predominantly based on ad valorem taxation, has guaranteed a growing flow of public revenues from tobacco until 2003. ${ }^{34}$ The structure of tobacco taxation has played an important role in producing this desirable public finance outcome. ${ }^{35}$ In competitive markets, specific and ad valorem taxes have identical consequences (Myles 1996). In the presence of monopoly, instead, ad valorem taxation leads to higher public revenues (Keen 1998) and lower prices. This explains the historical preference of the Italian government for ad valorem taxation. The existence of a public monopoly of tobacco in Italy between 1862 and 2003 has implied that the institution setting the price and determining the structure of commodity taxation was the same (the state), producing a taxation structure - in particular of cigarettes - that was heavily distorted in favor of ad valorem taxation (Manzioni, Pandimiglio, and Spallone 2011; Liberati and Paradiso 2014; Crespi et al. 2015). ${ }^{36}$

\footnotetext{
${ }^{31}$ Even though there is a huge body of literature on tobacco demand, only a few studies have estimated tobacco product demand in a system framework. Zheng et al. (2016) is an exception. The purpose of their study and the demand system composition is different from our own, though we can still make some comparisons. We find a long-run own price elasticity of demand for cigarettes in a similar range (-0.495 in Zheng et al. 2016). Both in Zheng et al. (2016) and in our study, cigarettes are by far the most price-inelastic among tobacco products.

${ }^{32}$ We thank an anonymous reviewer for suggesting using the Slutzky decomposition to deepen the analysis of substitution and complementarities relationships.

${ }^{33}$ To see this, consider the following iso-elastic demand function: $Q=A p^{-\eta}$ where $Q$ is quantity demanded and $p$ is price. Total expenditure is: $p Q=p A p^{-\eta}=A p^{1-\eta}$. Take $\eta=0.5$ for example. Total expenditure $p Q=A \sqrt{p}$ always increases with $p$ and is independent of $Q$. So an iso-elastic demand function with price elasticity less than one ensures increasing expenditures following a price increase even when quantity demanded is decreasing.

${ }^{34}$ In 2003 the management of the Italian market for tobacco passed from public monopoly to a private company named British and American Tobacco.

${ }^{35}$ Commodity taxation can mainly take the form either of specific or of ad valorem taxation. A specific tax (or unit tax) is defined as a fixed amount per unit of the taxed good or service, whereas an ad valorem tax is defined as a proportion of the product price and so, in effect, a tax on the sales value (Hines 2008).

${ }^{36}$ In the most recent years the share of ad valorem over total excise taxation in Italy was 0.87 (Crespi et al. 2015).
} 
The balance between ad valorem and specific taxation bears, however, important implications for public revenue certainty and stability. It is easily shown (Kay and Keen 1983; Keen 1998) that, when demand is iso-elastic, the optimal condition for stabilizing public revenues requires the share of ad valorem over total taxation to be equal to the price elasticity of demand. ${ }^{37}$ In mathematical terms,

$$
\frac{v p}{t+v p}=\eta
$$

where $\eta$ is the price elasticity of demand (defined as non-negative), $v p$ is the product between the rate of ad valorem tax (a proportion of the consumer price) and the consumer price $p$, and $t$ is the rate of specific taxation (a fixed amount per unit of the commodity). ${ }^{38}$ If, for a given structure of commodity taxation, $\frac{v p}{t+v p}>\eta$, a price increase will decrease public revenues; if, instead, $\frac{v p}{t+v p}<\eta$, a price increase will increase public revenues.

Italian governments have increased the share of ad valorem taxation over total taxation over time for the reasons explained above. Nowadays, however, the left-hand-side term of the optimality condition is around 0.90 and the absolute value of the price elasticity of demand, as found in our study, is around 0.5. Public revenues from tobacco excise taxation are actually decreasing (Marzioni, Pandimiglio, and Spallone 2011; Liberati and Paradiso 2014) and the share of ad valorem taxation should be reduced to meet the optimality condition for revenue stability. A different combination of tobacco taxation is desirable for other reasons as well. Kay and Keen (1983) show that ad valorem taxation should be used to correct non-price aspects of market performance (such as issues of quality and product variety), while specific taxation most powerfully affects prices and thus should be used to discourage consumption and reduce negative externalities. Furthermore, when externalities are large enough to require a policy intervention, the optimal tax structure switches immediately to wholly specific excise taxation (Pirttilä 1997). Empirical support is offered by Chaloupka et al. (2010), who provide evidence that cigarette consumption is less affected by an increase in an ad valorem excise tax than by a comparable increase in a specific excise tax. Thus, the reasons that the Italian tax authorities have adduced in the most recent years to justify high rates of taxation on tobacco-such as the desire to discourage consumption and its negative externalities - are the sort

\footnotetext{
${ }^{37}$ Following Key and Keen (1982), consider public revenues from taxation as given by the following equation: $R=(t+v p) Q$, where $\mathrm{R}$ is public revenues from taxation, $\mathrm{Q}$ is quantity demanded (which depends on price), $\mathrm{t}$ is the rate of specific taxation, and $\mathrm{vp}$ is the product between the rate of ad valorem taxation and the price. By setting the derivative of this equation with respect to $p$ to zero, we obtain: $\frac{d R}{d p}=t \frac{d Q}{d p}+v$ $p \frac{d Q}{d p}+v Q=0$ or $(t+v p) \frac{d Q}{d p}=-v Q$.

Multiplying both sides by $\frac{p}{Q}$, we obtain the optimality condition: $\frac{v p}{(t+v p)}=\frac{d Q}{d p} \frac{p}{Q}=\eta$.

${ }^{38}$ The maximizing condition neglects the fact that a change in the price of cigarettes, for example, will typically affect expenditure on the other tobacco products. The strength and direction of this effect depends on both the rates at which the other goods are taxed and the magnitude and sign of cross-price effects (Keen 1998). If two goods are complements, say, then the larger the absolute value of the crossprice elasticity, the larger the ratio of ad valorem taxation over total excise taxation in order to preserve constancy of the overall tax revenues. As a matter of fact, snuff and cut tobacco were both complements to cigarettes in the third sub-period (table 5). Changes in cigarette prices thus affected not only cigarette consumption, but also expenditures on snuff and cut tobacco. This allowed the government to further increase ad valorem excise taxation preserving constancy of the overall tax revenues.
} 
of arguments that should prompt high rates of specific rather than ad valorem taxation.

\section{Conclusions}

Traditionally, Italian policy makers have considered tobacco as a major source of public revenues while its health-related issues have been ignored altogether. Historical sources explicitly document the government's goal of increasing the level of domestic tobacco consumption to that prevailing in other European countries. However, society's opinion on tobacco consumption, in Italy as elsewhere, has changed dramatically over time. Our statistical analysis identifies the early 1980s as the period marking the reversal of the rising trend that started soon after the Second World War.

In light of these considerations, it was somewhat surprising to find, throughout our secular investigation (1871-2010), long-run price elasticities in the range of -0.6 to -0.5 at the sample mean, and also evidence that demand is nowadays becoming increasingly inelastic when growing health concerns could have triggered the opposite trend. ${ }^{39}$

Interestingly, it seems that Italian governments have for a long time been able to exploit this demand behavior for rising public revenues. However, the optimal condition for stabilizing public revenues from tobacco taxation does not seem to hold in the most recent years of our analysis, and this change of environment calls for a change in the taxation structure of tobacco products.

Our analysis also reveals an increasingly strong and asymmetric separability between cigarettes and other products, that is, while cigarette demand is insensitive to price variations in the other tobacco products, the converse does not hold. Public policy could exploit these cross-product relationships to incentivize the desired consumption behavior. Since smokeless forms of tobacco do not carry the same health hazards that passive smoking does, an active role in triggering desirable substitution or complementarity relationships could be played by introducing tax differentials for the different tobacco products.

\section{Supplementary Material}

Supplementary material is available at Applied Economic Perspectives and Policy online.

\section{References}

Adda, J., and F. Cornaglia. 2006. Taxes, Cigarette Consumption, and Smoking Intensity. American Economic Review 96: 1013-28.

Alberg, A.J., D.R. Shopland and K.M. Cummings. 2014. The 2014 Surgeon General's Report: Commemorating the 50th Anniversary of the 1964 Report of the Advisory Committee to the U.S. Surgeon General and Updating the Evidence on the Health Consequences of Cigarette Smoking. American Journal of Epidemiology 179: 403-12.

\footnotetext{
${ }^{39}$ One possible interpretation of this finding is that, as health concerns grow and more health-conscious smokers quit, only the more addicted smokers continue smoking. We thank a reviewer for suggesting this interpretation.
} 
Attfield, C.L.F. 1997. Estimating a Cointegrating Demand System. European Economic Review 41: 61-73.

Atti Parlamentari. 1878. Legislatura XIII, Sessione 1878, Documenti, Progetto di Legge 38a. Camera dei Deputati, Rome, Italy.

Atti Parlamentari. 1907. Legislatura XXII, 1a Sessione, Discussioni, Tornata del 9 febbraio. Camera dei Deputati, Rome, Italy.

Auld, P., and P. Grootendorst. 2004. An Empirical Analysis of Milk Addiction. Journal of Health Economics 23: 1117-23.

Baltagi, B.H., and D. Levin. 1986. Estimating Dynamic Demand for Cigarettes Using Panel Data: The Effects of Bootlegging, Taxation and Advertising Reconsidered. Review of Economics and Statistics 68: 148-55.

—. 1992. Cigarette Taxation: Raising Revenues and Reducing Consumption. Structural Change and Economic Dynamics 3: 321-35.

Baffigi, A. 2011. Italian National Accounts. A project of the Bank of Italy, Istat and University of Rome Tor Vergata. Economic History Working Papers 18, Bank of Italy.

Becker, G., M. Grossman, and K.M. Murphy. 1990. An Empirical Analysis of Cigarette Addiction. Working Paper n. 61-1990. Centre for the Study of the Economy and the State, University of Chicago.

— . 1994. An Empirical Analysis of Cigarette Addiction. The American Economic Review 84: 396-418.

Becker, G.S., and K. Murphy. 1988. A Theory of Rational Addiction. Journal of Political Economy 96: 675-700.

Binkley, J. 2010. Low Income and Poor Health Choices: The Example of Smoking. American Journal of Agricultural Economics 92 (4): 972-84.

Caiumi, A. 1992. Consumi alimentari, prezzi relativi e distribuzione, 1960-1990. Rivista di Economia Agraria 47: 407-20.

Cameron, S. 1998. Estimation of the Demand for Cigarettes: A Review of the Literature. Economic Issues 3 (2): 51-71.

Chaloupka, F. 1991. Rational Addictive Behavior and Cigarettes Smoking. Journal of Political Economy 99: 722-42.

Chaloupka, F.J., and K.E. Warner. 2000. The Economics of Smoking. In Handbook of Health Economics, Volume 1, Part B, ed. A.J. Culyerand J.P. Newhouse, 1539-627. Amsterdam: North Holland.

Chaloupka, F.J., R. Peck, J.A. Tauras, X. Xu, and A. Yurekli. 2010. Cigarette Excise Taxation: The Impact of Tax Structure on Prices, Revenues, and Cigarette Smoking. NBER Working Paper 16287. Available at: http:/ / www.nber.org/papers/w16287.

Ciccarelli, C. 2012. The Consumption of Tobacco in Italy, 1871-1913: National and Regional Estimates. Rivista di storia economica 28 (3): 409-52.

Ciccarelli, C., and G. De Fraja .2014. The Demand for Tobacco in Post-unification Italy. Cliometrica 8 (2): 145-71.

Ciccarelli, C., and J.P. Elhorst. Forthcoming. A Dynamic Spatial Econometric Diffusion Model with Common Factors: The Rise and Spread of Cigarette Consumption in Italy. Regional Science and Urban Economics.

Crespi, F., M. De Maria, P. Liberati, M. Paradiso, and A. Scialà. 2015. La riforma della tassazione dei tabacchi: effetti e criticità. Università degli Studi Roma Tre CEFIP Centro di Ricerca di Economia e Finanza Pubblica.

Cummings, K.M., and R.N. Proctor. 2014. The Changing Public Image of Smoking in the United States: 1964-2014. Cancer Epidemiology, Biomarkers \& Prevention 23: 32-36.

Deaton, A., and J. Muellbauer. 1980. An Almost Ideal Demand System. American Economic Review 70: 312-36.

Dickey, D.A., and W.A. Fuller. 1979. Distribution of the Estimators for Autoregressive Time Series with a Unit Root. Journal of the American Statistical Association 74: 427-31.

Engle, R.F., and C.W.J. Granger. 1987. Cointegration and Error Correction: Representation, Estimation, and Testing. Econometrica 55: 251-76. 
Escario, J.J., and J.A. Molina. 2001. Testing for the Rational Addiction Hypothesis in Spanish Tobacco Consumption. Applied Economics Letters 8: 211-5.

Farrelly, M.C., T.F. Pechacek, and F.J. Chaloupka. 2005. The Impact of Tobacco Control Program Expenditures on Aggregate Cigarette Sales: 1981-2000. Journal of Health Economics 22: 843-59.

Gallet, C.A., and J.A. List. 2003. Cigarette Demand: A Meta-Analysis of Elasticities. Health Economics 12: 821-35.

Gallus, S., E. Fernandez, J. Townsend, A. Schiaffino, and C. La Vecchia. 2003. Price and Consumption of Tobacco in Italy over the Last Three Decades. European Journal of Cancer Prevention 12: 333-7.

Gallus, S., I. Tramacere, P. Zuccaro, P. Colombo, and C. La Vecchia. 2009. Cigarette Smuggling in Italy, 2005-8. Tobacco Control 18: 159-60.

Gilmore, A.B., A. Rowell, S. Gallus, A. Lugo, L. Joossens, and M. Sims .2014. Towards a Greater Understanding of the Illicit Tobacco Trade in Europe: A Review of the PMI Funded "Project Star" Report. Tobacco Control 23: 51-61.

Green, R., and J.M. Alston. 1990. Elasticities in AIDS Models. American Journal of Agricultural Economics 72 (2): 442-5.

Gruber, J., A. Sen, and M. Stabile. 2003. Estimating Price Elasticities when There Is Smuggling: The Sensitivity of Smoking to Price in Canada. Journal of Health Economics 22: 821-42.

Hines, J.R. 2008. Excise Taxes. In The New Palgrave Dictionary of Economics, Second edition, Steven N. Durlauf and Lawrence E. Blume, eds. Palgrave Macmillan, 2008.

Houthakker, H., and L.D. Taylor. 1966. Consumer Demand in the United States, Analyses and Projections. Harvard Economic Studies, Harvard University Press, 1970.

Istat. 1987. Annuario statistico italiano, Rome.

Istat. 1999. Annuario statistico italiano, Rome.

Istat. 2011. L'Italia in 150 anni. Sommario di statistiche storiche 1861-2010, Avellino.

Johansen, S. 1988. Statistical Analysis of Cointegration Vectors. Journal of Economic Dynamics and Control 12: 231-54.

Jones, A., and M. Giannoni-Mazzi. 1996. Tobacco Consumption and Taxation in Italy. An Application of the QAIDS in Italy. Applied Economics 28: 595-603.

Joossens, L., and M. Raw. 2008. Progress in Combating Cigarette Smuggling: Controlling the Supply Chain. Tobacco Control 17: 399-404.

Joossens, L., A. Lugo, C. La Vecchia, A.B. Gilmore, L. Clancy, and S. Gallus. 2014. Illicit Cigarettes and Hand-Rolled Tobacco In 18 European Countries: A CrossSectional Survey. Tobacco Control 23: 17-23.

Kay, J.A., and M.J. Keen. 1982. The Structure of Tobacco Taxes in the European Community. Report Series 1, London, Institute for Fiscal Studies.

- 1983. How Should Commodities Be Taxed? Market Structure, Product Heterogeneity and the Optimal Structure of Commodity Taxes. European Economic Review 23: 339-58.

Keen, M.J. 1998. The Balance between Specific and ad valorem Taxation. Fiscal Studies 19: 1-37.

Kwiatkowski, D., P.C.B. Phillips, P. Schmidt and Y. Shin. 1992. Testing the Null Hypothesis of Stationarity against the Alternative of a Unit Root. Journal of Econometrics 54: 159-78.

La Vecchia, C. 1986. Smoking in Italy, 1949-1983. Preventive Medicine 15: 274-81.

Liberati, P., and M. Paradiso. 2014. On the Structure of The Excise Taxes on Tobacco: A Reform Proposal for Italy. MPRA Working Paper 55906.

MacKinnon, J.G. 1996. Numerical Distribution Functions for Unit Root and Cointegration Tests. Journal of Applied Econometrics 11: 601-18.

Madsen, A.W. 1916. The State as a Manufacturer And Trader. An Examination Based On The Commercial, Industrial, And Fiscal Results Obtained From Tobacco Monopolies. London: Wentworth Press.

Manera, G. 1963. La domanda di tabacco in Italia. Giuffrè, Milan. 
Marzioni, S., A. Pandimiglio, and M. Spallone. 2011. Analisi dell'Elasticità della Domanda nel Mercato dei Tabacchi Lavorati in Italia. Working Paper 6 2011; Arcelli Centre for Monetary and Financial Studies, Department of Economics and Business, LUISS Guido Carli.)

Myles, G.D. 1996. Imperfect Competition and the Optimal Combination of ad valorem and Specific Taxation. International Tax and Public Finance 3: 29-44.

National Cancer Institute. 1998. Cigars: Health Effects and Trends, Smoking and Tobacco Control. Tobacco Control Monograph Series n. 9. National Cancer Institute at the National Institutes of Health.

Ng, S., and P. Perron. 2001. Lag Length Selection and the Construction of Unit Root Tests with Good Size and Power. Econometrica 69 (6): 1519-54.

Nguyen, L., G. Rosenqvist, and M. Pekurinen .2012. Demand for Tobacco in Europe. An Econometric Analysis of 11 Countries for the PPACTE Project. Report 6/2012. National Institute for Health and Welfare.

O'Connor, R. 2011. Non-cigarette Tobacco Products: What Have We Learnt and Where Are We Headed? Tobacco Control 21: 181-90.

Perron, P.P. 1989. The Great Crash, the Oil Price Shock and the Unit Root Hypothesis. Econometrica 57: 1361-402.

Pierani, P., and S. Tiezzi. 2009. Addiction and Interaction Between Alcohol and Tobacco Consumption. Empirical Economics 37: 1-23.

Pirttilä, J. 1997. Aspects of Environmental Taxation under Imperfect Competition. Unpublished Manuscript. University of Essex.

Pollack, R.A. 1970. Habit Formation and Dynamic Demand Functions. Journal of Political Economy 78: 745-63.

Rizzi, P.L. 2000. Invecchiamento della popolazione e consumi privati in Italia, 19612020. La Questione Agraria 4-2000.

Rizzi, P.L., and F. Balli .2002. La domanda di consumo di beni non durevoli e servizi in Italia negli anni '90: analisi di breve periodo con un sistema Almost Ideal a due stadi. Quaderni del Dipartimento di Economia Politica 352- 2002 Università degli Studi di Siena.

Saffer, H., and F.J. Chaloupka. 1999. Tobacco Advertising: Economic Theory and International Evidence. Working Paper 6958, NBER, Cambridge, MA.

Scalzi, F. 1868. Il consumo del tabacco da fumo a Roma in attinenza alla salute pubblica. Kessinger Publishing, September 2010, Rome.

Schoenberg, E.H. 1933. The Demand Curve for Cigarettes. Journal of Business 6 (1): 15-35.

Sephton, P.S. 1995. Response Surface Estimates of the KPSS Stationarity Test. Economics Letters 47: 255-61.

Tiezzi, S. 2005. An Empirical Analysis of Tobacco Addiction in Italy. The European Journal of Health Economics 6: 233-43.

U.S. Department of Health, Education, and Welfare. 1964. Smoking And Health: Report of The Advisory Committee to the Surgeon General of the Public Health Service. Public Health Service publication no. 1103, Washington, DC.

Vetritto, G. 2005. La parabola di un'industria di stato. Marsilio, Venice.

Warner, K.E. 2014. 50 Years since the First Surgeon General's Report on Smoking and Health: A Happy Anniversary? American Journal of Public Health 104 (1): 5-8.

World Health Organization. 2011. WHO Report On The Global Tobacco Epidemic. Warning about The Dangers of Tobacco. Report of the WHO, Geneva, Switzerland.

Zheng, Y., C. Zhen, J. Nonnemaker, and D. Dench. 2016. Advertising, habit formation, and U.S. tobacco product demand. American Journal of Agricultural Economics, 98(4): 1038-1054. 